(2) Open Access Full Text Article

ORIGINAL RESEARCH

\title{
Improvement in pain severity category in clinical trials of pregabalin
}

\section{Bruce Parsons' \\ Charles E Argoff ${ }^{2}$ \\ Andrew Clair ${ }^{\prime}$ \\ Birol Emir ${ }^{1}$}

'Pfizer, New York, NY, USA; ${ }^{2}$ Albany Medical Center, Albany, NY, USA
Correspondence: Bruce Parsons

Pfizer, 235 East 42nd Street, New York, NY 10017 , USA

Tel + I 212573 1649

Email bruce.parsons@pfizer.com
This article was published in the following Dove Press journal:

Journal of Pain Research

7 October 2016

Number of times this article has been viewed

Background: Pregabalin is approved by the US Food and Drug Administration for the treatment of fibromyalgia (FM), diabetic peripheral neuropathy (DPN), postherpetic neuralgia (PHN), and neuropathic pain due to spinal cord injury (SCI). Approval was based on clinical trial data demonstrating statistically significant differences in pain scores versus placebo. However, statistically significant pain relief may not always equate to clinically meaningful pain relief. To further characterize the clinical benefit of pregabalin, this analysis examined shifts in pain severity categories in patients with FM, DPN/PHN (pooled in this analysis), and SCI treated with pregabalin.

Methods: Data were pooled from 23 placebo-controlled trials in patients with FM $(1,623$ treated with pregabalin, 937 placebo), DPN/PHN (2,867 pregabalin, 1,532 placebo), or SCI (181 pregabalin, 175 placebo). Pain scores were assessed on an 11-point numeric rating scale and categorized as mild ( 0 to $<4$ ), moderate $(4$ to $<7$ ), or severe ( 7 to 10$)$. Only patients with mean score $\geq 4$ at baseline were randomized to treatment. The percentage of patients shifting pain category from baseline to endpoint for pregabalin and placebo was analyzed using a modified ridit transformation with the Cochran-Mantel-Haenszel procedure.

Results: A higher proportion of patients shifted to a less severe pain category at endpoint with pregabalin compared with placebo. With flexible-dose pregabalin, the percentage of patients improving from: severe to mild (pregabalin versus placebo) was 15.8 versus 13.4 in FM patients, 36.0 versus 16.6 in DPN/PHN patients, 14.3 versus 7.7 in SCI patients; severe to moderate was 28.7 versus 28.2 in FM patients, 32.5 versus 28.2 in DPN/PHN patients, 35.7 versus 28.2 in SCI patients; and moderate to mild was 38.3 versus 26.4 in FM patients, 59.5 versus 41.4 in DPN/ PHN patients, 38.6 versus 27.2 in SCI patients.

Conclusion: Compared with placebo, pregabalin is more often associated with clinically meaningful improvements in pain category in patients with FM, DPN, PHN, or SCI.

Keywords: fibromyalgia, diabetic peripheral neuropathy, postherpetic neuralgia, neuropathic pain, pooled analysis

\section{Introduction}

The pain intensity experienced by patients with chronic pain conditions is often delineated into the categories of mild, moderate, and severe. ${ }^{1}$ These categories attempt to reflect the degree of interference a patient's pain has on their ability to function and can be linked to patient outcomes and health resource utilization. ${ }^{1-3}$ It is important to note that the relationship between a pain severity score and the degree of interference on patient function is not always linear, meaning that an equivalent change in pain score may not always equate to the same degree of change in function. ${ }^{1,2}$ As a result, while 
statistical difference from placebo (or from other treatment) is a necessary and important outcome measure, taken on its own it may not always represent clinically meaningful pain relief, while pain relief may not always represent clinically meaningful changes in function.

Pregabalin is an $\alpha 2 \delta$ ligand indicated in the United States for the treatment of a range of chronic pain conditions including fibromyalgia (FM) and neuropathic pain associated with diabetic peripheral neuropathy (DPN), postherpetic neuralgia (PHN), and spinal cord injury (SCI). ${ }^{4}$ Pregabalin is also indicated as adjunctive therapy for partial seizures. ${ }^{4}$ The efficacy of pregabalin in these chronic pain conditions was demonstrated in a number of randomized, placebo-controlled trials in which pregabalin treatment improved mean pain score when compared with placebo. ${ }^{5-26}$ However, how directly improvements in mean pain score relate to clinical and functional benefits for patients is not always clear.

In this pooled analysis of patient-level data from all chronic pain conditions for which pregabalin is a US Food and Drug Administration (FDA)-approved treatment option, shifts in pain severity category following treatment were examined. Shifts in pain severity with pregabalin were compared with placebo to further understand the clinical impact of pregabalin treatment.

\section{Methods}

\section{Study design}

This was an analysis of 23 randomized, placebo-controlled, parallel-group, double-blind trials of pregabalin. Patient-level data were pooled into three groups: patients with FM, patients with DPN or PHN, and patients with neuropathic pain due to SCI. FM patient data were from five trials (ClinicalTrials.gov identifiers: NCT00645398, NCT00230776, NCT00333866, NCT00830167):22-26 conducted between September 1999 and May 2011; ranging from 8 to 15 weeks in duration; including doses of $300 \mathrm{mg} /$ day, $450 \mathrm{mg} /$ day, and flexible dosing (optimized to 300 or $450 \mathrm{mg}$ /day during the first 3 weeks of the trial after which patients continued on their optimized dose). DPN and PHN patient data were pooled from nine studies in patients with DPN (NCT00156078, NCT00159679, NCT00143156, NCT00553475), ${ }^{5-7,10-13}$ five studies in patients with PHN (NCT00159666), ${ }^{7,14-17}$ and two studies in patients with either painful DPN or PHN (NCT00301223): ${ }^{18,19}$ conducted between March 1998 and March 2009; ranging in duration from 5 to 16 weeks; including doses of $150 \mathrm{mg} /$ day, $300 \mathrm{mg} /$ day, $450 \mathrm{mg} /$ day, and flexible dosing (150-600 mg/day in which dosage adjustments, based on tolerability, were allowed for the first 3 weeks after which the patient remained on their optimized dose for the remainder of the trial). SCI patient data were from two trials of 12 -week ${ }^{20}$ and 16 -week (NCT00407745) ${ }^{21}$ duration conducted between June 2002 and February 2011, with flexible dosing (150-600 mg/day dosage adjustments for the first 3 or 4 weeks). This includes all Pfizer-sponsored randomized, placebo-controlled, parallel-group, double-blind trials of pregabalin in these patient populations completed before this analysis was initiated.

All patients were $\geq 18$ years of age and had an average pain score $\geq 4$ on the 11-point numeric rating scale (NRS), where $0=$ no pain and $10=$ worst possible pain, during the study screening period, with four or more pain diaries completed. Patients in the FM trials had a primary diagnosis of FM according to the 1990 American College of Rheumatology criteria for $\mathrm{FM}^{27}$ (widespread pain present for $\geq 3$ months and pain in $\geq 11$ of 18 tender points). Patients in the DPN trials had a diagnosis of type 1 or type 2 diabetes mellitus with painful, symmetrical sensorimotor polyneuropathy for $\geq 6$ months (or, in one trial, $\geq 3$ months). ${ }^{5}$ Patients in the PHN trials had experienced neuropathic pain for $\geq 3$ months following healing of the herpes zoster viral rash (or, in one trial, $\geq 6$ months). ${ }^{15}$ Patients in the SCI trials had a complete or incomplete SCI of $\geq 12$-months' duration, with chronic pain experienced continuously for $\geq 3$ months or with remissions and relapses for $\geq 6$ months.

The protocols for all trials adhered to the International Ethical Guidelines for Biomedical Research Involving Human Subjects, the International Conference on Harmonisation Good Clinical Practice guidelines, and the Helsinki Declaration. All trials were approved by the appropriate institutional review board and all patients provided written informed consent prior to participation.

\section{Efficacy measures}

Patients rated their pain over the previous 24 hours on the $\operatorname{NRS}(0=$ no pain and $10=$ worst possible pain $)$. Pain scores were categorized as mild ( 0 to $<4)$, moderate $(\geq 4$ to $<7$ ), or severe $(\geq 7$ to $\leq 10))^{2,28}$ The percentage of patients shifting, from baseline to endpoint, from one pain severity category to another was calculated for placebo- and pregabalin-treated patients (patients with mild pain at baseline were excluded from the analysis). Patients shifting from severe to mild were considered "very much improved" ( 2 category shift). Patients shifting from severe to moderate or from moderate to mild were considered "much improved" (1 category shift). Patients remaining in the same pain category were classified as "no change". Patients shifting to a more severe pain category were classified as "worsened". 
Change in Fibromyalgia Impact Questionnaire (FIQ) total score was assessed in four of the five FM trials (one of the trials did not record FIQ). ${ }^{23}$ The FIQ is a 20 -item self-administered, psychometrically validated questionnaire designed to assess health status, progress, and outcomes in patients with FM. ${ }^{29}$ The FIQ total score assesses the effect of FM symptoms with a total score range of $0-100$, with higher scores indicating greater impairment. ${ }^{29}$ FIQ total scores were categorized as mild $(0$ to $<39)$, moderate $(39$ to $<59)$, or severe ( $\geq 59$ to 100$).{ }^{30}$ The percentage of patients shifting, from baseline to endpoint, from one FIQ severity category to another was calculated as described above for pain scores.

\section{Statistical analysis}

Pregabalin and placebo groups were compared and statistical significance was assessed by using a Cochran-MantelHaenszel test with modified ridit (modridit) transformation of the calculated ordinal shift scales. Missing data were imputed by baseline observation carried forward.

\section{Results}

\section{Study population}

Patient-level data were pooled into the following groups: 2,560 patients with FM (1,623 pregabalin and 937 placebo), 4,399 patients with DPN/PHN (2,867 pregabalin and 1,532 placebo), and 356 patients with SCI (181 pregabalin and 175 placebo). Baseline demographic characteristics were similar for different treatment arms within each condition (Table 1).

\section{Shift in pain category}

Patients with FM, DPN/PHN, and SCI were more likely to improve in pain category at endpoint with pregabalin than with placebo (Table 2).

In patients with FM, there was a trend toward improvement in pain category compared with placebo with pregabalin at $300 \mathrm{mg} /$ day $(P=0.013)$, pregabalin $450 \mathrm{mg} /$ day $(P<0.001)$, and flexible-dose pregabalin $(P=0.138)$ (Table 2$)$. When compared with pregabalin at 300 or $450 \mathrm{mg} /$ day, flexible-dose pregabalin was more likely to result in patients being "much improved" at endpoint but less likely to result in patients being "very much improved" (Figure 1). While there were differences with different doses of pregabalin, when all pregabalin-treated patients were combined the improvement in pain category at endpoint was statistically significant compared with placebo $(P<0.001)$.

In patients with DPN/PHN, pain category at endpoint compared with placebo was improved with pregabalin 150 $\mathrm{mg} /$ day $(P=0.001), 300 \mathrm{mg} /$ day $(P<0.001), 600 \mathrm{mg} /$ day $(P<0.001)$, and flexible-dose pregabalin $(P<0.001)$ (Table 2$)$. A shift to an improved pain category was more common with flexible-dose pregabalin than with any of the fixed doses, but pregabalin at $300 \mathrm{mg} /$ day and $600 \mathrm{mg} /$ day also resulted in shifts to improved pain categories (Figure 2).

In patients with SCI, pain category at endpoint was improved with flexible-dose pregabalin compared with placebo $(P=0.010)$ (Table 2$)$. As with patients with FM or DPN/PHN, patients with SCI were more likely to shift to a

Table I Patient demographics at baseline

\begin{tabular}{|c|c|c|c|c|c|c|c|c|c|c|c|}
\hline & \multicolumn{4}{|l|}{$\mathbf{F M}$} & \multicolumn{5}{|c|}{ DPN/PHN } & \multicolumn{2}{|l|}{ SCI } \\
\hline & \multicolumn{3}{|c|}{ Pregabalin, mg/d } & \multirow{2}{*}{$\begin{array}{l}\text { Placebo } \\
(\mathrm{N}=937)\end{array}$} & \multicolumn{4}{|c|}{ Pregabalin, mg/d } & \multirow{2}{*}{$\begin{array}{l}\text { Placebo } \\
(\mathrm{N}=1,532)\end{array}$} & \multirow{2}{*}{$\begin{array}{l}\text { Pregabalin, } \\
\text { mg/d } \\
\text { Flex } \\
(\mathrm{N}=|8|)\end{array}$} & \multirow{2}{*}{$\begin{array}{l}\text { Placebo } \\
(N=\mid 75)\end{array}$} \\
\hline & $\begin{array}{l}300 \\
(N=686)\end{array}$ & $\begin{array}{l}450 \\
(N=687)\end{array}$ & $\begin{array}{l}\text { Flex } \\
(N=250)\end{array}$ & & $\begin{array}{l}150 \\
(N=427)\end{array}$ & $\begin{array}{l}300 \\
(N=875)\end{array}$ & $\begin{array}{l}600 \\
(N=86 I)\end{array}$ & $\begin{array}{l}\text { Flex } \\
(N=704)\end{array}$ & & & \\
\hline \multicolumn{12}{|l|}{ Sex, n (\%) } \\
\hline Male & $\begin{array}{l}52 \\
(7.6)\end{array}$ & $\begin{array}{l}47 \\
(6.8)\end{array}$ & $\begin{array}{l}24 \\
(9.6)\end{array}$ & $\begin{array}{l}81 \\
(8.6)\end{array}$ & $\begin{array}{l}227 \\
(53.2)\end{array}$ & $\begin{array}{l}491 \\
(56.1)\end{array}$ & $\begin{array}{l}492 \\
(57.1)\end{array}$ & $\begin{array}{l}326 \\
(46.3)\end{array}$ & $\begin{array}{l}824 \\
(53.8)\end{array}$ & $\begin{array}{l}144 \\
(79.6)\end{array}$ & $\begin{array}{l}146 \\
(83.4)\end{array}$ \\
\hline Female & $\begin{array}{l}634 \\
(92.4)\end{array}$ & $\begin{array}{l}640 \\
(93.2)\end{array}$ & $\begin{array}{l}226 \\
(90.4)\end{array}$ & $\begin{array}{l}856 \\
(91.4)\end{array}$ & $\begin{array}{l}200 \\
(46.8)\end{array}$ & $\begin{array}{l}384 \\
(43.9)\end{array}$ & $\begin{array}{l}369 \\
(42.9)\end{array}$ & $\begin{array}{l}378 \\
(53.7)\end{array}$ & $\begin{array}{l}708 \\
(46.2)\end{array}$ & $\begin{array}{l}37 \\
(20.4)\end{array}$ & $\begin{array}{l}29 \\
(16.6)\end{array}$ \\
\hline \multicolumn{12}{|l|}{ Race, n (\%) } \\
\hline White & $\begin{array}{l}599 \\
(87.3)\end{array}$ & $\begin{array}{l}598 \\
(87.0)\end{array}$ & $\begin{array}{l}0 \\
(0.0)\end{array}$ & $\begin{array}{l}602 \\
(64.2)\end{array}$ & $\begin{array}{l}411 \\
(96.3)\end{array}$ & $\begin{array}{l}677 \\
(77.4)\end{array}$ & $\begin{array}{l}737 \\
(85.6)\end{array}$ & $\begin{array}{l}296 \\
(42.1)\end{array}$ & $\begin{array}{l}1,101 \\
(71.9)\end{array}$ & $\begin{array}{l}109 \\
(60.2)\end{array}$ & $\begin{array}{l}109 \\
(62.3)\end{array}$ \\
\hline Black & $\begin{array}{l}23 \\
(3.4)\end{array}$ & $\begin{array}{l}23 \\
(3.3)\end{array}$ & $\begin{array}{l}0 \\
(0.0)\end{array}$ & $\begin{array}{l}19 \\
(2.0)\end{array}$ & $\begin{array}{l}7 \\
(1.6)\end{array}$ & $\begin{array}{l}30 \\
(3.4)\end{array}$ & $\begin{array}{l}39 \\
(4.5)\end{array}$ & $\begin{array}{l}13 \\
(1.9)\end{array}$ & $\begin{array}{l}57 \\
(3.7)\end{array}$ & $\begin{array}{l}6 \\
(3.3)\end{array}$ & $\begin{array}{l}8 \\
(4.6)\end{array}$ \\
\hline $\begin{array}{l}\text { Asian/ } \\
\text { other }\end{array}$ & $\begin{array}{l}64 \\
(9.3)\end{array}$ & $\begin{array}{l}66 \\
(9.6)\end{array}$ & $\begin{array}{l}250 \\
(100.0)\end{array}$ & $\begin{array}{l}316 \\
(33.7)\end{array}$ & $\begin{array}{l}9 \\
(2.1)\end{array}$ & $\begin{array}{l}168 \\
(19.2)\end{array}$ & $\begin{array}{l}85 \\
(9.9)\end{array}$ & $\begin{array}{l}395 \\
(56.1)\end{array}$ & $\begin{array}{l}374 \\
(24.4)\end{array}$ & $\begin{array}{l}66 \\
(36.5)\end{array}$ & $\begin{array}{l}58 \\
(33.1)\end{array}$ \\
\hline $\begin{array}{l}\text { Age, years, } \\
\text { mean (SD) }\end{array}$ & $\begin{array}{l}48.9 \\
(10.7)\end{array}$ & $\begin{array}{l}48.9 \\
(11.4)\end{array}$ & $\begin{array}{l}47.9 \\
(12.0)\end{array}$ & $\begin{array}{l}48.3 \\
(11.6)\end{array}$ & $\begin{array}{l}65.3 \\
(12.3)\end{array}$ & $\begin{array}{l}64.2 \\
(12.3)\end{array}$ & $\begin{array}{l}61.1 \\
(10.9)\end{array}$ & $\begin{array}{l}60.6 \\
(10.5)\end{array}$ & $\begin{array}{l}62.4 \\
(11.7)\end{array}$ & $\begin{array}{l}47.7 \\
(13.5)\end{array}$ & $\begin{array}{l}47.2 \\
(14.1)\end{array}$ \\
\hline
\end{tabular}


Table 2 Patients in each pain severity category at endpoint

\begin{tabular}{|c|c|c|c|c|c|c|c|}
\hline & Treatment & $\mathbf{N}$ & $\begin{array}{l}\text { Baseline pain } \\
\text { category }\end{array}$ & $\begin{array}{l}\text { Mild pain at } \\
\text { endpoint, } n \text { (\%) }\end{array}$ & $\begin{array}{l}\text { Moderate pain at } \\
\text { endpoint, } n(\%)\end{array}$ & $\begin{array}{l}\text { Severe pain at } \\
\text { endpoint, } n(\%)\end{array}$ & $\begin{array}{l}P \text {-value versus } \\
\text { placebo }\end{array}$ \\
\hline \multirow[t]{8}{*}{ FM } & Pregabalin $300 \mathrm{mg} / \mathrm{d}$ & 686 & Moderate & $83(26.9)$ & $200(64.7)$ & $26(8.4)$ & 0.013 \\
\hline & & & Severe & $68(18.3)$ & $108(29.0)$ & $196(52.7)$ & \\
\hline & Pregabalin 450 mg/d & 687 & Moderate & $99(30.3)$ & $208(63.6)$ & $20(6.1)$ & $<0.001$ \\
\hline & & & Severe & 69 (19.9) & $108(31.1)$ & $170(49.0)$ & \\
\hline & Pregabalin Flex ${ }^{a}$ & 250 & Moderate & $57(38.3)$ & $80(53.7)$ & $12(8.0)$ & 0.138 \\
\hline & & & Severe & $16(15.8)$ & $29(28.7)$ & $56(55.4)$ & \\
\hline & Placebo & 937 & Moderate & $133(26.4)$ & $320(63.5)$ & $51(10.1)$ & - \\
\hline & & & Severe & $57(13.4)$ & $120(28.2)$ & $248(58.3)$ & \\
\hline \multirow[t]{10}{*}{ DPN/PHN } & Pregabalin $150 \mathrm{mg} / \mathrm{d}$ & 427 & Moderate & $104(42.6)$ & $129(52.9)$ & II (4.5) & 0.001 \\
\hline & & & Severe & $33(19.3)$ & $46(26.9)$ & $92(53.8)$ & \\
\hline & Pregabalin $300 \mathrm{mg} / \mathrm{d}$ & 875 & Moderate & $233(44.1)$ & $270(51.1)$ & $25(4.7)$ & $<0.001$ \\
\hline & & & Severe & $93(27.8)$ & $88(26.3)$ & $153(45.8)$ & \\
\hline & Pregabalin $600 \mathrm{mg} / \mathrm{d}$ & 861 & Moderate & $234(46.6)$ & 247 (49.2) & $21(4.2)$ & $<0.001$ \\
\hline & & & Severe & $126(37.2)$ & $75(22.1)$ & I 38 (40.7) & \\
\hline & Pregabalin Flex & 704 & Moderate & $235(59.5)$ & $152(38.5)$ & $8(2.0)$ & $<0.001$ \\
\hline & & & Severe & $104(36.0)$ & $94(32.5)$ & 91 (3I.5) & \\
\hline & Placebo & 1,532 & Moderate & $366(4 I .4)$ & $464(52.4)$ & $55(6.2)$ & - \\
\hline & & & Severe & $102(16.6)$ & $173(28.2)$ & $339(55.2)$ & \\
\hline \multirow[t]{4}{*}{$\mathrm{SCl}$} & Pregabalin Flex & 174 & Moderate & 39 (38.6) & $61(60.4)$ & I (I.0) & 0.010 \\
\hline & & & Severe & $10(14.3)$ & $25(35.7)$ & $35(50.0)$ & \\
\hline & Placebo & 173 & Moderate & $25(27.2)$ & $61(66.3)$ & $6(6.5)$ & - \\
\hline & & & Severe & $6(7.7)$ & $22(28.2)$ & $50(64.1)$ & \\
\hline
\end{tabular}

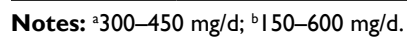

Abbreviations: DPN, diabetic peripheral neuropathy; Flex, flexible dosing; FM, fibromyalgia; PHN, postherpetic neuralgia; SCl, spinal cord injury; d, day.

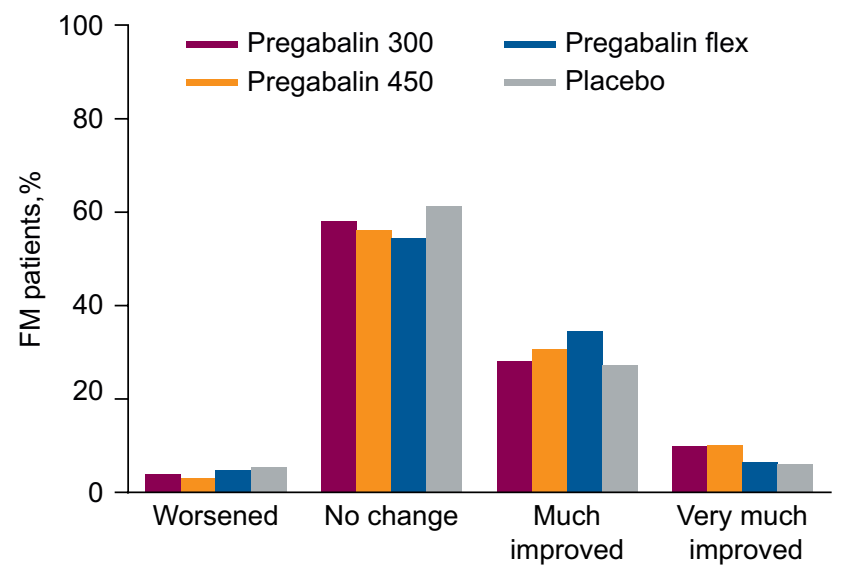

Figure I Shift in pain severity category from baseline to endpoint for FM patients. Notes: Proportion of FM patients with a shift in pain category that was "very much improved" (severe to mild), "much improved" (moderate to mild, or severe to moderate), "no change", or "worsened" (moderate to severe, mild to moderate, or mild to severe). $P=0.013$ for pregabalin $300 \mathrm{mg} / \mathrm{d}$ versus placebo; $P<0.001$ for pregabalin $450 \mathrm{mg} / \mathrm{d}$ versus placebo; and $P=0.138$ for pregabalin flex versus placebo. Abbreviations: flex, flexible dosing; FM, fibromyalgia; d, day.

"much improved" category than a "very much improved" category (Figure 3).

Patients were generally more likely to shift pain category if they were classified as severe at baseline. For example, Table 2 shows that for pregabalin $450 \mathrm{mg}$ /day in FM patients, $49.0 \%$ of patients with severe pain at baseline remained in the severe

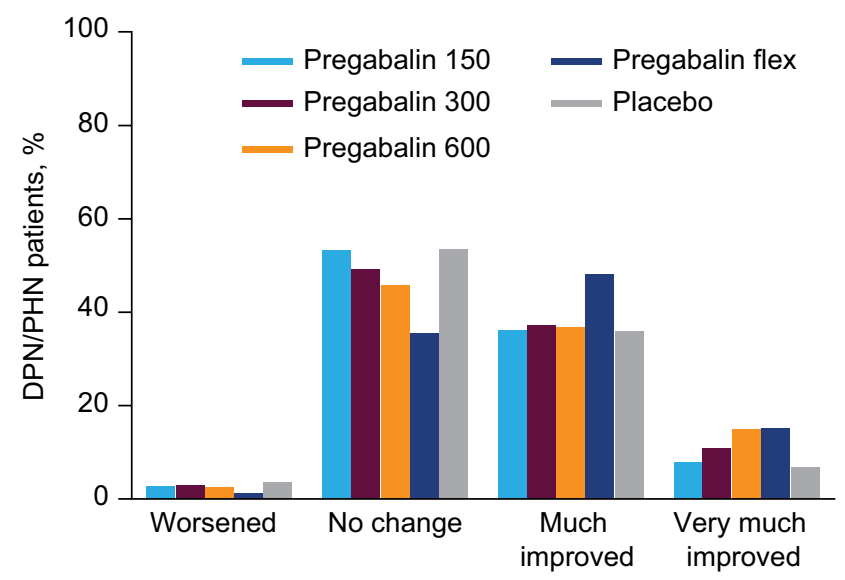

Figure 2 Shift in pain severity category from baseline to endpoint for DPN/PHN patients.

Notes: Proportion of DPN/PHN patients with a shift in pain category that was "very much improved" (severe to mild), "much improved" (moderate to mild, or severe to moderate), "no change", or "worsened" (moderate to severe, mild to moderate, or mild to severe). $P \leq 0.00 \mathrm{I}$ for each dose of pregabalin versus placebo. Abbreviations: DPN, diabetic peripheral neuropathy; flex, flexible dosing; PHN, postherpetic neuralgia.

category at endpoint, notably lower than the $63.6 \%$ of patients with moderate pain at baseline remaining in the moderate category at endpoint. There was a similar trend in each of the chronic pain conditions examined, for example, flexible-dose pregabalin in patients with DPN/PHN (31.5\% severe, $38.5 \%$ moderate) and SCI (50.0\% severe, $60.4 \%$ moderate). 


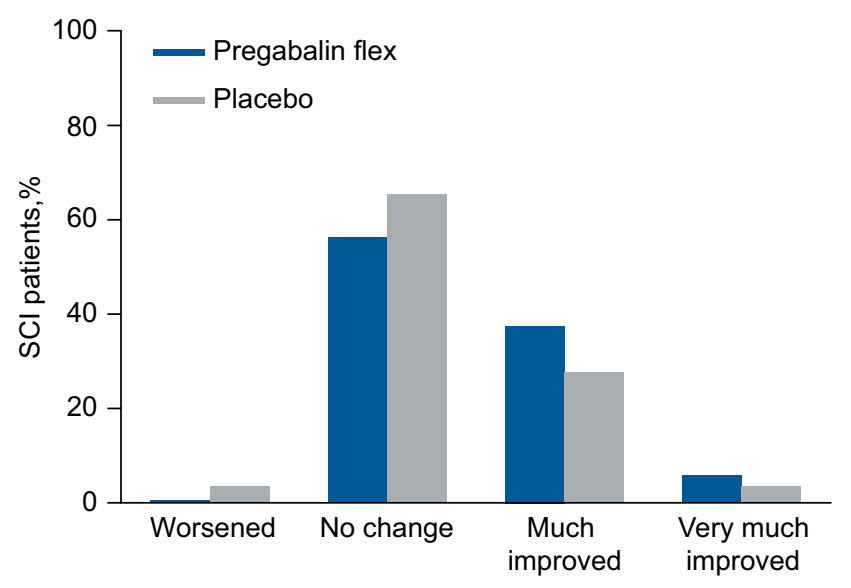

Figure 3 Shift in pain severity category from baseline to endpoint for $\mathrm{SCl}$ patients. Notes: Proportion of $\mathrm{SCl}$ patients with a shift in pain category that was "very much improved" (severe to mild), "much improved" (moderate to mild, or severe to moderate), "no change", or "worsened" (moderate to severe, mild to moderate, or mild to severe). Studies in patients with $\mathrm{SCl}$ utilized pregabalin flexible dose only. $P=0.010$, for pregabalin versus placebo.

Abbreviations: flex, flexible dosing; $\mathrm{SCl}$, spinal cord injury.

\section{Shift in FIQ total score category}

While shifts in FIQ category from baseline to endpoint occurred in $36.6 \%-42.2 \%$ of patients with FM, shifts were not significantly different from placebo for pregabalin $300 \mathrm{mg} /$ day $(P=0.965)$, pregabalin $450 \mathrm{mg} /$ day $(P=0.136)$, or flexible-dose pregabalin $(P=0.313)$. There was a trend toward a greater proportion of patients being "very much improved" (shifting from severe to mild) with pregabalin $300 \mathrm{mg} /$ day (10.1\%) and pregabalin $450 \mathrm{mg} /$ day (13.2\%), compared with placebo $(7.6 \%)$ and flexible-dose pregabalin $(6.8 \%)$, but this was not significant.

\section{Discussion}

Chronic pain conditions such as neuropathic pain associated with DPN, PHN, and SCI, together with FM, are often challenging to treat and have a significant impact on patients and their health-related quality of life. ${ }^{31-33}$ This analysis assessed the clinical impact of pregabalin treatment in each of these conditions as they represent all of the chronic pain conditions for which pregabalin is an FDA-approved treatment option. ${ }^{4}$ The analysis sought to further assess the clinical impact of pregabalin treatment.

The use of pain categories mild, moderate, and severe were initially characterized in patients with chronic cancer pain, ${ }^{1}$ and they have since been beneficial in research and in developing treatment approaches/algorithms in many chronic pain conditions. ${ }^{34-36}$ These categories are based on the impact of pain on patient function but also reflect patients' own assessment of their pain. ${ }^{2}$ As such, changes in pain category can be considered both clinically meaningful and as having a real impact for patients.
In this analysis, DPN/PHN, SCI, and FM patients with severe pain at baseline were nearly twice as likely to shift to mild pain at endpoint (ie, were "very much improved") if they received treatment with pregabalin as opposed to placebo. Patients were also more likely to shift to moderate from severe, or mild from moderate, with pregabalin than with placebo. Overall, patients with DPN/PHN were more likely to shift to an improved pain category than patients with SCI or FM. The most notable change was in patients with DPN/PHN with severe baseline pain treated with flexible dose pregabalin, where $68.5 \%$ shifted to an improved pain category. In patients with SCI or FM, a small majority of patients did not shift pain category. This was also true for patients with DPN/PHN treated with placebo or low-dose pregabalin (150 mg/day). With higher doses of pregabalin (450 mg/day and flexible dosing), the majority of patients with DPN/PHN shifted to an improved pain category.

In patients with FM in this analysis, flexible-dose pregabalin was less likely to result in a shift in pain category than fixed doses of $300 \mathrm{mg} /$ day and $450 \mathrm{mg}$ /day. This was, perhaps, unexpected given the optimal approach is typically to carefully titrate pregabalin to the highest tolerable dose, ${ }^{37-39}$ which in this analysis would be more closely represented by the flexible dosing group. This observation was not consistent with the assessment of patients with DPN/PHN where flexible-dose pregabalin had a greater effect than fixed doses. The trials in patients with SCI included in this analysis only used flexible-dose pregabalin, which had a significantly greater effect than placebo. The average daily pregabalin dose in one study in patients with DPN/PHN over the full treatment period was $372.2 \mathrm{mg} /$ day. ${ }^{18}$ In patients with SCI, the average daily dose of pregabalin over both studies was $370.0 \mathrm{mg} /$ day ${ }^{40}$ In the study in patients with FM, 178 of 250 patients $(71.2 \%)$ received pregabalin $450 \mathrm{mg}$ /day and 72 patients $(28.8 \%)$ received $300 \mathrm{mg}$ /day during the maintenance phase (ie, an average dose of $\sim 400 \mathrm{mg} /$ day) ${ }^{25} \mathrm{As}$ such, the difference in the effect of flexible-dose pregabalin between patient groups is unlikely to be due to differences in the average dose of pregabalin.

It should be noted that all patients with FM receiving flexible-dose pregabalin in this analysis were from a single study $^{25}$ conducted solely in Japanese patients. The majority of patients with FM in the other trials in this analysis were from the United States: Three trials were conducted in patients in the United States exclusively, ${ }^{22-24}$ while one trial was in patients in Europe, Canada, Mexico, India, Korea, Australia, and Venezuela. ${ }^{26}$ There may be cultural or racial characteristics of Japanese patients with FM that make them less likely to shift pain category than patients with FM in the United States or Europe. 
Alternatively, the differences in the flexible-dose group may be related to differences in baseline pain. In general, patients were more likely to shift pain category if they had severe pain at baseline. The mean (standard deviation) baseline pain scores were lower in the flexible-dose FM population: 6.5 (1.3) in the flexible-dose pregabalin group compared with 7.0 (1.3) and 6.8 (1.4) in the pregabalin $300 \mathrm{mg} /$ day and 450 $\mathrm{mg} /$ day groups, respectively. In addition, a lower proportion of patients were categorized as severe at baseline in the flexibledose pregabalin group (40.4\%) than in the pregabalin 300 $\mathrm{mg} /$ day $(54.2 \%$ ) or pregabalin $450 \mathrm{mg} /$ day (50.5\%) groups.

Previous analyses have supported the suggestion that pregabalin has a greater impact on pain, and symptoms, in patients with severe pain at baseline. These include an analysis of pregabalin clinical trials in patients with DPN that showed a greater mean change in pain score at endpoint versus placebo with pregabalin in patients with severe baseline pain compared with moderate baseline pain. ${ }^{41}$ The analysis also revealed greater improvements with pregabalin in patients' pain-related sleep interference and global impression of change. ${ }^{41}$ In patients with FM, pregabalin (at $300 \mathrm{mg}$ / day and $450 \mathrm{mg} /$ day) also led to a greater mean change in pain score at endpoint versus placebo in patients with severe pain at baseline than in patients with moderate pain at baseline. ${ }^{42}$ The data reported here demonstrate that this observation extends to changes in pain category, supporting the concept that this difference is clinically meaningful.

In this analysis, a change in FIQ category at endpoint was as common as a change in pain category. Across all treatment groups, $36.6 \%-42.2 \%$ of patients with FM changed FIQ category at endpoint compared with $38.9 \%-45.6 \%$ of patients with FM who changed pain category. However, there was no difference in the proportion of patients changing pain category with pregabalin than with placebo. It is not clear why significant changes in pain did not translate to significant changes in FIQ category. Pregabalin significantly improved FIQ total score at endpoint compared with placebo in the majority of trials in this analysis. ${ }^{22,24,25}$ Severity categories based on FIQ score are perhaps less well established than those for pain scores, and it may be that the category divisions currently used do not always directly relate to clinically important changes. As such, this analysis of FIQ scores may be of limited benefit.

Another limitation of this analysis is that the data were pooled from a large number of studies conducted under different conditions and in different countries with the trials grouped by pain categories. At the same time, this also suggests that these findings may be broadly applicable. Finally, this was a post hoc analysis of these data with the trials not designed with the primary aim to assess changes in pain severity category.
The data in this analysis suggest that the established efficacy of pregabalin for improving pain scores in patients with neuropathic pain due to DPN, PHN, and SCI, and in patients with FM also extends to clinically meaningful improvements in pain category.

\section{Acknowledgments}

This study was sponsored by Pfizer. Medical writing support was provided by Joshua Fink, $\mathrm{PhD}$, of Engage Scientific Solutions, and funded by Pfizer.

\section{Disclosure}

$\mathrm{BP}, \mathrm{AC}$, and BE are employees of Pfizer and hold stock options in Pfizer. CEA has received research grants for his institution as a principal investigator from Endo, Forest, and Lilly; has received honoraria as a consultant and advisor to Pfizer and Teva; has received honoraria as a consultant to Daiichi Sankyo, Purdue, and Nextar; has received honoraria as an advisor and speaker from Depomed, XenoPort, and Iroko; and has received honoraria as a speaker from Millenium Labs, Janssen, and Allergan. The authors report no other conflicts of interest in this work.

\section{References}

1. Serlin RC, Mendoza TR, Nakamura Y, Edwards KR, Cleeland CS. When is cancer pain mild, moderate or severe? Grading pain severity by its interference with function. Pain. 1995;61(2):277-284.

2. Zelman DC, Dukes E, Brandenburg N, Bostrom A, Gore M. Identification of cut-points for mild, moderate and severe pain due to diabetic peripheral neuropathy. Pain. 2005;115(1-2):29-36.

3. Schaefer C, Sadosky A, Mann R, et al. Pain severity and the economic burden of neuropathic pain in the United States: BEAT neuropathic pain observational study. Clinicoecon Outcomes Res. 2014;6:483-496.

4. Lyrica $^{\circledR}$ (pregabalin). Prescribing Information. New York, NY, USA: Pfizer Inc; 2011. Available from: http://labeling.pfizer.com/ShowLabeling.aspx?id=561. Accessed March 9, 2016.

5. Arezzo JC, Rosenstock J, Lamoreaux L, Pauer L. Efficacy and safety of pregabalin $600 \mathrm{mg} / \mathrm{d}$ for treating painful diabetic peripheral neuropathy: a double-blind placebo-controlled trial. BMC Neurol. 2008;8:33.

6. Lesser H, Sharma U, LaMoreaux L, Poole RM. Pregabalin relieves symptoms of painful diabetic neuropathy: a randomized controlled trial. Neurology. 2004;63(11):2104-2110.

7. Sharma U, Griesing T, Emir B, Young JP Jr. Time to onset of neuropathic pain reduction: a retrospective analysis of data from nine controlled trials of pregabalin for painful diabetic peripheral neuropathy and postherpetic neuralgia. Am J Ther. 2010;17(6):577-585.

8. Pfizer Inc. A 14-week, double-blind, randomized, placebo-controlled, multicenter study to evaluate the safety and efficacy of pregabalin (150mg-600mg/day) using a flexible optimal dose schedule in patients with painful diabetic peripheral neuropathy (DPN). Available from: https:/clinicaltrials.gov/ct2/show/NCT00156078. NLM identifier: NCT00156078. Accessed July 12, 2016.

9. Pfizer Inc. A randomized, double-blind, placebo-controlled, parallel-group, multi-center trial of pregabalin versus placebo in the treatment of neuropathic pain associated with diabetic peripheral neuropathy. Available from: https://clinicaltrials.gov/ct2/show/NCT00143156. NLM identifier: NCT00143156. Accessed July 12, 2016.

10. Richter RW, Portenoy R, Sharma U, Lamoreaux L, Bockbrader H, Knapp LE. Relief of painful diabetic peripheral neuropathy with pregabalin: a randomized, placebo-controlled trial. J Pain. 2005;6(4):253-260. 
11. Rosenstock J, Tuchman M, LaMoreaux L, Sharma U. Pregabalin for the treatment of painful diabetic peripheral neuropathy: a double-blind, placebo-controlled trial. Pain. 2004;110(3):628-638.

12. Satoh J, Yagihashi S, Baba M, et al. Efficacy and safety of pregabalin for treating neuropathic pain associated with diabetic peripheral neuropathy: a 14 week, randomized, double-blind, placebo-controlled trial. Diabet Med. 2011;28(1):109-116.

13. Tölle T, Freynhagen R, Versavel M, Trostmann U, Young JP Jr. Pregabalin for relief of neuropathic pain associated with diabetic neuropathy: a randomized, double-blind study. Eur J Pain. 2008;12(2):203-213.

14. Dworkin RH, Corbin AE, Young JP Jr, et al. Pregabalin for the treatment of postherpetic neuralgia: a randomized, placebo-controlled trial. Neurology. 2003;60(8):1274-1283.

15. Sabatowski R, Gálvez R, Cherry DA, et al. Pregabalin reduces pain and improves sleep and mood disturbances in patients with post-herpetic neuralgia: results of a randomised, placebo-controlled clinical trial. Pain. 2004;109(1-2):26-35.

16. Stacey BR, Barrett JA, Whalen E, Phillips KF, Rowbotham MC. Pregabalin for postherpetic neuralgia: placebo-controlled trial of fixed and flexible dosing regimens on allodynia and time to onset of pain relief. J Pain. 2008;9(11):1006-1017.

17. van Seventer R, Feister HA, Young JP Jr, Stoker M, Versavel M, Rigaudy L. Efficacy and tolerability of twice-daily pregabalin for treating pain and related sleep interference in postherpetic neuralgia: a 13-week, randomized trial. Curr Med Res Opin. 2006;22(2):375-384.

18. Freynhagen R, Strojek K, Griesing T, Whalen E, Balkenohl M. Efficacy of pregabalin in neuropathic pain evaluated in a 12-week, randomised, double-blind, multicentre, placebo-controlled trial of flexible- and fixed-dose regimens. Pain. 2005;115(3):254-263.

19. Guan Y, Ding X, Cheng Y, et al. Efficacy of pregabalin for peripheral neuropathic pain: results of an 8-week, flexible-dose, double-blind, placebocontrolled study conducted in China. Clin Ther. 2011;33(2):159-166.

20. Siddall PJ, Cousins MJ, Otte A, Griesing T, Chambers R, Murphy TK. Pregabalin in central neuropathic pain associated with spinal cord injury: a placebo-controlled trial. Neurology. 2006;67(10):1792-1800.

21. Cardenas DD, Nieshoff EC, Suda K, et al. A randomized trial of pregabalin in patients with neuropathic pain due to spinal cord injury. Neurology. 2013;80(6):533-539.

22. Arnold LM, Russell IJ, Diri EW, et al. A 14-week, randomized, doubleblinded, placebo-controlled monotherapy trial of pregabalin in patients with fibromyalgia. J Pain. 2008;9(9):792-805.

23. Crofford LJ, Rowbotham MC, Mease PJ, et al. Pregabalin for the treatment of fibromyalgia syndrome: results of a randomized, double-blind, placebo-controlled trial. Arthritis Rheum. 2005;52(4):1264-1273.

24. Mease PJ, Russell IJ, Arnold LM, et al. A randomized, double-blind, placebo-controlled, phase III trial of pregabalin in the treatment of patients with fibromyalgia. J Rheumatol. 2008;35(3):502-514.

25. Ohta H, Oka H, Usui C, Ohkura M, Suzuki M, Nishioka K. A randomized, double-blind, multicenter, placebo-controlled phase III trial to evaluate the efficacy and safety of pregabalin in Japanese patients with fibromyalgia. Arthritis Res Ther. 2012;14(5):R217.
26. Pauer L, Winkelmann A, Arsenault P, et al. An international, randomized, double-blind, placebo-controlled, phase III trial of pregabalin monotherapy in treatment of patients with fibromyalgia. J Rheumatol. 2011;38(12):2643-2652.

27. Wolfe F, Smythe HA, Yunus MB, et al. The American College of Rheumatology 1990 criteria for the classification of fibromyalgia. Report of the Multicenter Criteria Committee. Arthritis Rheum. 1990;33(2):160-172.

28. Hanley MA, Masedo A, Jensen MP, Cardenas D, Turner JA. Pain interference in persons with spinal cord injury: classification of mild, moderate, and severe pain. J Pain. 2006;7(2):129-133.

29. Burckhardt CS, Clark SR, Bennett RM. The fibromyalgia impact questionnaire: development and validation. J Rheumatol. 1991;18(5):728-733.

30. Bennett RM, Bushmakin AG, Cappelleri JC, Zlateva G, Sadosky AB. Minimal clinically important difference in the fibromyalgia impact questionnaire. J Rheumatol. 2009;36(6):1304-1311.

31. Doth AH, Hansson PT, Jensen MP, Taylor RS. The burden of neuropathic pain: a systematic review and meta-analysis of health utilities. Pain. 2010; 149(2):338-344.

32. Murray RF, Asghari A, Egorov DD, et al. Impact of spinal cord injury on self-perceived pre- and postmorbid cognitive, emotional and physical functioning. Spinal Cord. 2007;45(6):429-436.

33. Arnold LM, Crofford LJ, Mease PJ, et al. Patient perspectives on the impact of fibromyalgia. Patient Educ Couns. 2008;73(1):114-120.

34. Dworkin RH, Turk DC, Wyrwich KW, et al. Interpreting the clinical importance of treatment outcomes in chronic pain clinical trials: IMMPACT recommendations. J Pain. 2008;9(2):105-121.

35. Ritchlin CT, Kavanaugh A, Gladman DD, et al. Treatment recommendations for psoriatic arthritis. Ann Rheum Dis. 2009;68(9):1387-1394.

36. Kapstad H, Hanestad BR, Langeland N, Rustoen T, Stavem K. Cutpoints for mild, moderate and severe pain in patients with osteoarthritis of the hip or knee ready for joint replacement surgery. BMC Musculoskelet Disord. 2008;9:55

37. Attal N, Cruccu G, Baron R, et al. EFNS guidelines on the pharmacological treatment of neuropathic pain: 2010 revision. Eur J Neurol. 2010;17(9):1113-e1188.

38. Freeman R, Durso-Decruz E, Emir B. Efficacy, safety, and tolerability of pregabalin treatment for painful diabetic peripheral neuropathy: findings from seven randomized, controlled trials across a range of doses. Diabetes Care. 2008;31(7):1448-1454.

39. Freynhagen R, Serpell M, Emir B, et al. A comprehensive drug safety evaluation of pregabalin in peripheral neuropathic pain. Pain Pract. 2015;15(1):47-57.

40. Parsons B, Sanin L, Yang R, Emir B, Juhn M. Efficacy and safety of pregabalin in patients with spinal cord injury: a pooled analysis. Curr Med Res Opin. 2013;29(12):1675-1683.

41. Parsons B, Li C. The efficacy of pregabalin in patients with moderate and severe pain due to diabetic peripheral neuropathy. Curr Med Res Opin. 2016;32(5):929-937.

42. Clair A, Emir B. The efficacy of pregabalin for treating fibromyalgia patients with moderate or severe baseline widespread pain. Arthritis Rheumatol. 2014;66(S10):S1879 [Abstract]
Journal of Pain Research

\section{Publish your work in this journal}

The Journal of Pain Research is an international, peer reviewed, open access, online journal that welcomes laboratory and clinical findings in the fields of pain research and the prevention and management of pain. Original research, reviews, symposium reports, hypothesis formation and commentaries are all considered for publication.
The manuscript management system is completely online and includes a very quick and fair peer-review system, which is all easy to use. Visit http://www.dovepress.com/testimonials.php to read real quotes from published authors. 